\title{
Obesity in Pakistan; Current and Future Perceptions
}

\author{
Maira Siddiqui ${ }^{1}$, Hareem Ayub ${ }^{1}$, Rabia Hameed ${ }^{1}$, Muhammad Ilyas Nadeem $^{2,4}$,TengkuAriff Mohammad ${ }^{3}$, \\ Nordin Simbak², Ahmad Zubaidi A Latif², Yasrullzad Abubakar² and Atif Amin Baig²*
}

${ }^{1}$ Food Science \& Technology, Jinnah University for Women, Pakistan

${ }^{2}$ Faculty of Medicine, Universiti Sultan Zainal Abidin, Malaysia

${ }^{3}$ Universiti Sultan Zainal Abidin, Malaysia

${ }^{4}$ Faculty of Health and Life Sciences, MSU, Malaysia

Submission: September 24, 2018; Published: November 14, 2018

*Corresponding author: Atif Amin Baig, Faculty of Medicine, Universiti Sultan Zainal Abidin, Malaysia

\begin{abstract}
Obesity is currently one of the most common health issues that is increasing day by day, and nearly $30 \%$ of world population is overweight or obese. More than $60 \%$ of global disease burden will be attributed to chronic disorder associated with obesity by 2020 according to WHO. Obesity is also a cause of many non-communicable diseases (NCD) due to which globally $60-70 \%$ deaths occur. Pakistan being the 9 th most obese nation in the world suffering from its epidemic, affecting all age group, especially in children and females as compared to men and its ratio will be doubled in coming years due to high carbohydrate intake and physical inactivity and other environmental factors. Nutrigenetics and nutrigenomics which represent a unique approach in nutrition research, combining the application of powerful functional genomics technologies and play an important role in development and treatment of obesity and these preventive measures are required at the population level to control this global health issue.
\end{abstract}

Keywords: Burden, Epidemic, Nutrigenetics, Nutrigenomics, Carbohydrate, Global health, Chronic disorders, Overweight,

Abbreviations: CVD: Cardiovascular Disorders; NCD: Non-Communicable Disease; BMI: Body Mass Index; WHO: World Health Organization

\section{Introduction}

Obesity is a state that is associated with having overindulgence of body fat, defined by genetic and environmental factors that are hard to control with dieting. There is a difference in between overweight and obesity [1]. Overweight denotes the occurrence of the excess of body weight. Obesity denotes the presence of high amount of body fat. All obese people are overweight, but all overweight persons are not inevitably obese in excess.

A fat cell is an endocrine cell and adipose tissue is endocrine organ. As such, adipose tissue secretes some products, like metabolites, cytokines, lipids and coagulation factors. Significantly, excess adiposity or obesity causes the increased level of circulating fatty acids and inflammation. This can lead to insulin resistance, which in turn can cause type 2 diabetes $[1,2]$. Facts about overweight and obesity: some recent WHO global estimates follow; in 2016, more than 1.9 billion adults aged $\geq 18$ years were overweight. Of these over 650 million adults were obese, the worldwide prevalence of obesity nearly tripled from 1975-2016. Overweight and obesity are linked to more deaths worldwide than underweight. Globally there are more people who are obese than underweight in every region.

Causes and Health Consequences of Overweight and Obesity

There are several factors that may include weighting gain among adults and youth including genes, eating habits, physical inactivity, TV, computer, phone and other sleep routine, medical conditions or medications, and where and how people live (their inhabitation) and their choice of food [3,4].The obesity was classified as per WHO obesity criteria (WHO, 200) based on BMI.

\section{Obesity in Pakistan}

As per examine WHO states that around $26 \%$ women in Pakistan, suffer from the trouble of obesity while just $19 \%$ of the men are obese. Report of 2013 exposed that the rate was $28 \%$ for men and $38 \%$ for women, which is a huge gap between the two genders. Obesity is higher in urban areas (56\% in men and $67 \%$ in women) as compared to rural areas. Even in youth obesity is also growing at a fast pace. As per 2013 statistics, it was $10 \%$, which is a massive figure. In 2010 , approximately 3.4 million people expired because of obesity [5].

Pakistan is a country where the perception of the healthy diet among the general community is different. Pakistani diet is typically energy dense with a higher percentage of saturated fats, Tran's fatty acid and free sugar contributing to high calories intake. Use of ghee, high intake of meat, judicious use of sweets in celebrating imperative events of life is common dietary practices in Pakistan. Due to accelerating prices of staple food like cereal, vegetables, and fruits, mostly people favor the cheaper ways of energy like fats and sugar. Use of industrially processed food, fast food, junk food, and sugared fizzy drink are getting very trendy in the younger generation. Rapid urbanization and 
modernization are also leading to the constructive high fat diet instead of traditional low-fat diet [6-8].

\section{Studies on Obesity in Pakistan}

Pakistan is a developing country facing a "double burden", comprising disease associated with under development issues leading to poor quality of life (infectious disease and nutritional deficiencies) and non-communicable disorders secondary to urbanization or rapid industrialization. In Pakistan, contributory factors are environmental changes, urbanization, lifestyles modification, consumption of high-density diets, and decrease physical activity, which have resulted in rising burden of overweight and obesity. Studies have identified the variable burden of overweight and obesity among various populations distinct by gender and age groups, including children. Furthermore, various studies have identified the substantial increase in the burden of obesity particularly among children, comprising 43 percent of Pakistan's total population [9].

In Pakistan, Urban population, particularly women show considerable higher burden of obesity as compared to men and women from the rural population. Girls from all age groups are predominantly more obese as compared to boys. Most of the studies have estimated child obesity among school going children of different age and need careful interpretation [9].

A study conducted in northern areas of Pakistan had described an age-adjusted prevalence of overweight and obesity around $13.5 \%$ and $14.1 \%$ for men and women respectively and an increase in prevalence per year equally for both men and women [9]. Another study was conducted in the city of Multan, Pakistan considering the new recommended BMI cut-off for Asians found $46 \%$ of the people were overweight and obese, while $24.55 \%$ were underweight [9].

The reason for such drastic increase in obesity in Pakistani population is an unawareness of the harmful effect in the long run. Approximately 52\% of overweight and $73 \%$ of obese people have not even identified their problem, and they think that it's normal. People think it as a symbol of health, and they are not aware of the possible hazards to their health which can be caused by their excessive weight, therefore, they rarely try to lose weight. For Pakistan to progress, it is important that awareness created among the population regarding the harmful effects of weight gain, not only for themselves but also for the whole economy. Research indicates that people living in large cities in Pakistan are more exposed to the risks of obesity as compared to those in the rural countryside. Pakistan also has the highest-percentage of people with diabetes in south Asia. According to one study, "fat" is more dangerous for south Asians than for Caucasians because the fat tends to cling to organs like the liver instead of the skin.

\section{Obesity and its Incidence Reported in Pakistan}

Pakistan, being the 6thmost populated country in the world has $39.1 \%$ of urban population. Pakistan is a developing country, and it faces a lot of crises in health sector due to unawareness. In 2015, around 56.4 million deaths occurred globally and of it, $70 \%$ death caused by non-communicable disease (NCD). Most common NCDs include cardiovascular disorders (CVD), diabetes, and cancer. Around 455 deaths of all NCD occurred due to CVD, 1.6 million deaths due to diabetes and 8.8 million death due to cancer. It is easy to say that obesity came along with other diseases which can be a major issue and it is proven from many types of research that obesity is a major cause of NCD leading to severe cardiovascular problems, diabetes and premature death. In Pakistan, $46 \%$ of deaths occur due to NCD of about 380,000 in males and 300,000 in females and majority of NCD death linked to obesity.

On the other hand, obesity believed for approximately 80 $85 \%$ in developing the risk of type 2 diabetes it is estimated that diabetic patients will rise to 13.9 million by 2020 and obese people are 80 times more likely to develop type 2 diabetes. Many studies reveal the fact that abdominal fat causes fat cells to release pro-inflammatory chemicals due to which body cells become sensitive to insulin and altering the function of insulin responsive cells and their ability to respond to insulin. Today our country is in a phase where diabetes is very common and affects people at every age, and most of the cases of diabetes are directly linked to obesity [10-13].

Many health problems like high blood pressure, myocardial infarction, and hypertension are the risk factors for stroke. Moderate elevation of arterial blood pressure leads to shortened life expectancy. All these factors increase the risk of heart disease. Asthma, cancer and cancer-related mortality, sleep apnea, osteoarthritis and gynaecological complications are also related with obesity. In Pakistan, 30 to $40 \%$ of all death is caused by CVD. The CHD death in Pakistan has reached about 200,000 per year that is $410 / 100,000$ of the total population. CVD mortality and morbidity has been shown to be elevated in individuals that are overweight, particularly with central deposition of fat [1416].

Currently due to ease of access to food and minimal physical activity and because of globalization of processed food and fast food as it is much cheaper than healthy food, urbanization, socioeconomic status (are the factors) due to which one-fourth population of Pakistan lie in the category of overweight as per Asian specific BMI. In Khyber Medical University Journal, a study was conducted which showed that $16.2 \%$ of the student were obese and $15 \%$ were overweight, showing that younger generation of Pakistan is at increased risk of mortality and morbidity because of obesity-related complication and disease [6].

\section{Lipid Profiles}

Fats, or lipids, are the third main class of the macronutrients needed in human nutrition. The lipids are found primarily in meat and dairy food, at least, these are the most visible sources, but 
most foods contain some fats. Fats are an important component of our diet, and at least a minimum intake is essential. However, many problems are associated with excessive intake of dietary fat, including obesity, cardiovascular disease, and some forms of cancer. An important component of lipids is the fatty acids.

Levels of fat intake are highly correlated with weight. High consumption of dietary fat is associated with both increased body fat and obesity. Fats are the most concentrated source of food energy, supplying nine calories per gram, more than doubles the calorie content of the protein and carbohydrates [17]. Besides getting fattier, we are also developing more metabolic disorders, such as type 2 diabetes, which is marked by hormonal abnormalities in the processing and storage of nutrient and is far more common in obese individuals than in lean ones [18]. Genetic factors also have a strong influence on obesity and are associated with body mass index (BMI). Eating behaviour has been linked to the FTO gene in humans. FTO affects eating behavior and influence obesity [19-21].

\section{Recommendations}

Pakistan being 9th most obese nation [19] requires developing a national stratagem to control obesity in its populace by implementing the recommendation of the WHO global strategy on a diet, physical movement and health. The accomplishment program should integrate all stakeholders like health department, print and social media, nongovernmental institution, and private sectors. The major focal point should be the measures compulsory for

a. Rising the public awareness about the healthy diet, physical activities and its impact on public health.

b. Education programs in school and colleges should be approved from corner to corner to the country regarding healthy eating habits and promoting physical activities in younger generation

c. Legislation with appropriate implementation of schoolbased programs for sports and physical activities should be ensured.

d. Sports grounds and stadium amenities may be provided in every city.

e. The nation should be mobilized to adopt the habit of regular physical activity of 150 minutes per week for adult and 60 minutes for children.

f. Special emphasis may be laid on a healthy diet and avoiding the use of extra fats and sugar for energy. People should encourage for utilizing fresh fruits and vegetables, fruits, legumes, whole grains and higher fibers diets [6]. g. By adopting a healthy life style, using balanced diet and ensuring enough physical activities, we may be able to maintain normal weight and health.

\section{References}

1. World Health Organization (2017) Obesity and overweight.

2. Ilyas M, Atif A, Al-Hatamleh M, Al-Shajrawi O, Ariff T, et al. (2017) Rising Trends of Obesity in Malaysia; Role of Inflammation and Inflammatory Markers in Obesity Related Insulin Resistance: A Nuclear Factor Kappa B (Nfkb) Perspective. Curr Trends Biomedical Eng \& Biosci 10(4): 555793.

3. Katherine M, Flegal, Barry I, Graubard, David F, et al. (2005) Excess Deaths Associated with Underweight, Overweight, and Obesity JAMA 293: 1861-1867.

4. Ullah S, Ghani NA, Baig AA (2018) A Systematic Review of DeterminantSocial Factors Related to Obesity among Malays Obese Community in Malaysia. 8(5): 61-73.

5. Nutright Blog Obesity in Pakistan (2017) The Alarming stats 2017.

6. Sherin A (2013) Obesity: How to prevent Pakistani people from getting heavier? KMUJ: Khyber Medical University Journal 5: 2.

7. World Health Organization (2011) Burden: mortality, morbidity and risk factors. Chapter 1. In: Global status report on noncommunicable diseases 2010. Description of the global burden of NCDs, their risk factors and determinants.

8. World Health Organization (2011) NCD Country Profiles, 2011, Pakistan.

9. Tanzil S, Jamali T (2016) Obesity, An Emerging Epidemic in Pakistan-A Review of evidence. Research gate p. 3 .

10. Choo V (2002) WHO reassesses appropriate body-mass index for Asian populations. The Lancet 360(9328): 235.

11. Worldometers info Pakistan Population (2018) World meters.

12. Eckel R (1997) obesity and heart disease. Aha journals 96: 9.

13. Kuczmarski RJ, Flegal KM, Campbell SM, Johnson CL (1994) Increasing prevalence of overweight among U.S. adults: The National Health and Nutrition Examination Survey. JAMA 272: 205-211.

14. Diabetes co uk (2017) Diabetes and Obesity.

15. World Health Organization (2017) NCD mortality and morbidity.

16. Akil L, Ahmad H (2011) Relationships between Obesity and Cardiovascular Diseases in Four Southern States and Colorado. Journal of Health Care for the Poor and Underserved 22(4A): 61-72.

17. Zmark net Z (2017) Building Blocks of Nutrition: Fats, Lipids and Oils Healthy net.

18. Pakistan $9^{\text {th }}$ most obese country (2014) Study. The Express Tribune by AFP 2014.

19. Taubes G (2013) what-makes-you-fat-too-many-calories-or-thewrong-carbohydrates. Scientific American.

20. Insulin and Insulin Resistance (2005) Gisela Wilcox in Clinical Biochemist Reviews 26(2): 19-39.

21. Wells JC, Siervo M (2011) Obesity and Energy Balance: Is the Tail Wagging the Dog? Eur J Clin Nutr 65(11): 1173-1189. 
This work is licensed under Creative Commons Attribution 4.0 License DOI: 10.19080/CTBEB.2018.17.555958

\section{Your next submission with Juniper Publishers} will reach you the below assets

- Quality Editorial service

- Swift Peer Review

- Reprints availability

- E-prints Service

- Manuscript Podcast for convenient understanding

- Global attainment for your research

- Manuscript accessibility in different formats ( Pdf, E-pub, Full Text, Audio)

- Unceasing customer service

Track the below URL for one-step submission https://juniperpublishers.com/online-submission.php 